\title{
Progress in regional systems of care for STEMI in low- and middle-income countries
}

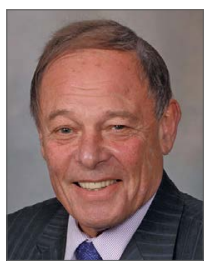

Bernard J. Gersh ${ }^{1 *}$, MB, Ch.B., D.Phil, FRCP, MACC; Christopher B. Granger², MD

1. Department of Cardiovascular Medicine, Mayo Clinic, Rochester, MN, USA; 2. Duke University, Duke Clinical Research Institute, Durham, NC, USA

"If you want to go fast, go alone; if you want to go far, go together". - An African proverb

Approximately 40 years ago, the sentinel animal experimental studies of Reimer and Jennings ${ }^{1}$, in addition to pioneering clinical studies by Sherry ${ }^{2}$ and Chazov $^{3}$ among others, and the pivotal GISSI I trial ${ }^{4}$ ushered in the reperfusion era - a therapeutic revolution that has transformed acute myocardial infarction (MI) care, and has also called for systems to provide rapid care, since the benefit of reperfusion is time-dependent. Soon afterwards, the introduction of primary angioplasty was a further advance ${ }^{5-7}$. I (BJG) clearly remember our first patient at the Mayo Clinic treated by my colleague Dr David Holmes. The patient was a woman in her 60 s with a large anterior MI presenting with Killip class 3 symptoms. Within an hour of restoration of blood flow in the left anterior descending coronary artery, the improvement was so dramatic and rapid that it brought home to us that, with regard to the management of ST-elevation myocardial infarction (STEMI), life would never be the same again. In fact, estimates are that timely primary percutaneous coronary intervention (PPCI) reduces mortality from STEMI by over $50 \%{ }^{8}$, making it one of the most effective treatments in all of medicine.
Decades later, despite an abundance of hard data from randomised clinical trials, registries, and guidelines, challenges remain in the application of reperfusion for acute MI (Figure 1). We know what to do; PPCI is the best form of therapy and a worthy goal ${ }^{8}$ but we also know that one size does not fit all in that timely PPCI is not always possible in which case fibrinolysis is the best option ${ }^{8-11}$. Strategies for the implementation of reperfusion therapy depend on physical constraints including geography, weather, distance, traffic, 9-1-1 system (Editor's note: North American emergency telephone number system), access to ambulances and coordination of services both in individual institutions and across regions. The fact is that, for the majority of people in the world (particularly those living in low- and middle-income countries), the pharmacoinvasive strategy is the main feasible and logical option ${ }^{8,10}$. Some of the better resourced centres in urban areas of low- and middle-income countries have already adopted the first stage of regional systems of care, such as transfer from non-PCI centres for patients with contraindications to and/or failure of fibrinolytics. 


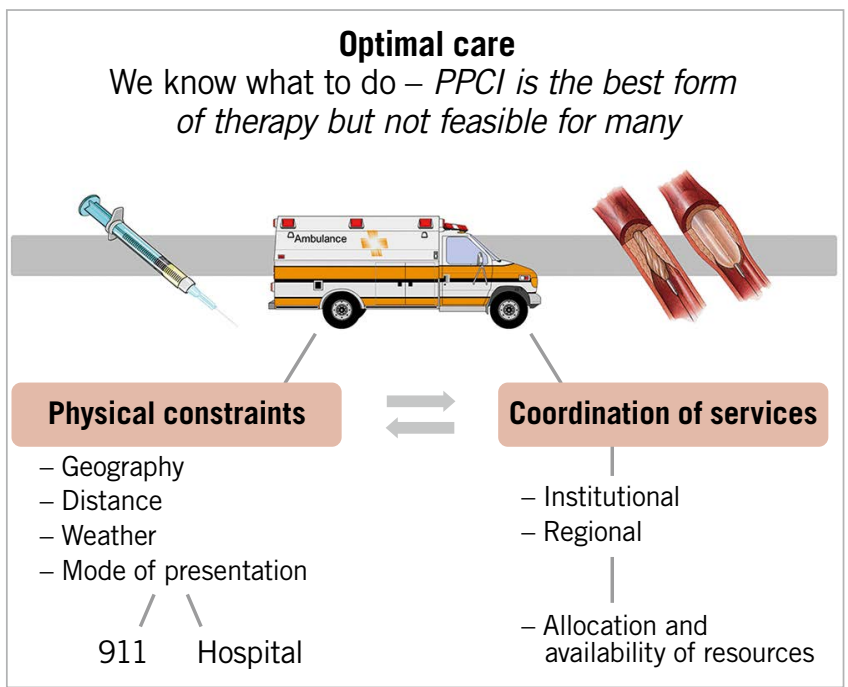

Figure 1. Local and regional factors which may impact on the success rates and methods of reperfusion for STEMI in a community.

Recent guidelines from both Europe and the USA give a Class 1 recommendation to the establishment of networks to provide reperfusion therapy for patients with STEMI in the community (Figure 2$)^{12}$. Such a network needs clear and well-articulated goals and these must be evidence based. It needs to adjust to local conditions, be simple to follow, and be available 24 hours a day and seven days a week. There needs to be universal "buy-in" from all stakeholders, and processes of care and outcomes need to be continuously audited and adapted to new knowledge.

Class I indication $=$ ESC 2017 guidelines
- Clear and well articulated goals
- Evidence based
- Enhance the speed and delivery of reperfusion
therapy to all eligible patients
- Adjust to local conditions
- Clearly defined roles - universal buy-in
- Simple to follow - $24 / 7$
- Continuous audit
- Adapt to new knowledge

Figure 2. Principles of a community reperfusion network.

Two studies in this issue of AsiaIntervention ${ }^{13,14}$ illustrate the benefits of thinking outside the box in adapting systems to local conditions. We have long been admirers of the work of Thomas Alexander and Ajit Mullasari, who have addressed the formidable logistical challenges of developing a STEMI management regional system in the Indian state of Tamil Nadu, which in turn can serve as a model for the development of systems in other low- and middle-income countries ${ }^{13}$.

\section{Article, see page 27}

The achievements of these investigators have indeed been impressive and were facilitated by the active participation of local government, the state ambulance network (approved by the government), and the government funded health insurance scheme for Below Poverty Level citizens. The crux of the system is the hub-and-spoke model, with PPCI the therapy of choice in the PPCI-capable hospital, and a pharmacoinvasive approach utilised in spoke hospitals. The goals were to reduce the proportion of patients receiving no reperfusion therapy and those who receive stand-alone fibrinolysis. What is important is that the authors have identified not only the unique features underpinning the success of this project, which can perhaps be generalised to other areas of the world, but also the unresolved issues. This makes for salutary reading and is of value for programmes both in India and in other countries around the world.

Transfer of knowledge is often a two-way street. One might ask whether this experience in a country such as India can provide a lesson to those of us living in high-income countries. In many parts of Europe, with the combination of shorter distances, excellent transport systems and the presence of many PCI-capable hospitals, PPCI can be the near universal approach. This is not the case in the USA, with its size, geographical disparity, and severe weather systems. Some states have worked with all their hospitals and emergency medical service (EMS) systems to establish protocols for early diagnosis, transportation to the appropriate centres, and choice of reperfusion therapy ${ }^{11}$. Nonetheless, a large US National Cardiovascular Data Registry of fibrinolysis use in patients requiring inter-hospital transfer for PPCI demonstrated disturbingly long drive times and a low use of fibrinolytic drugs during transfer ${ }^{15}$. Moreover, a substantial number of patients did not fall within the guideline-directed door-to-balloon time window of less than 120 minutes $^{12}$. Clearly, at least from a guideline standpoint, we are not doing as well as we think we are and we need to understand, adapt and individualise the way we treat patients in our own areas. Recently, we have also witnessed the stark reality of the impact of the COVID-19 pandemic on patients with acute coronary syndromes ${ }^{16}$. Times to hospital presentation and first door-to-balloon times were strikingly prolonged, with a dramatic adverse impact on mortality and rates of cardiogenic shock. These data reinforce both dramatically and tragically the time-honoured concept of "time is muscle" $", 8,17$.

Now to move to an entirely different part of the world, with its own unique challenges. Samir Mehta and his team describe the impact of a population-based telemedicine initiative on the efficiency of reperfusion strategies ${ }^{14}$.

\section{Article, see page 18}

The Latin American Telemedicine Infarct Network (LATIN) was developed with the laudable goal of serving poor and remote areas of Brazil and Colombia. The network strategically connects small clinics and primary care health centre spokes to hubs which have 24-hour PPCI capability. The key link is provided by experts 
at three sites who provide electrocardiogram (ECG) interpretation with telemedicine consultation.

Remarkably, over 300,000 patients were remotely screened, with an acute MI diagnosed in $1.1 \%$, among whom $45.8 \%$ received urgent reperfusion therapy. When comparing outcomes with historical pre-LATIN controls (an imperfect but nonetheless reasonable statistical comparison under the circumstances), the telemedicine strategy was associated with improved reperfusion rates with PPCI and reduced PPCI mortality, but not improved rates of overall mortality, and the increase in costs was relatively small. The authors should be congratulated on the establishment of a sophisticated system that reached a large number of patients in remote and poor areas of both countries. This project is an excellent example of the burgeoning use of telemedicine and is likely to be applicable to many parts of the world, subject to local modifications. The study also identified areas for further improvement, including a rather disappointing lack of reperfusion therapy in approximately $50 \%$ of patients, primarily due to lack of intensive care unit (ICU) beds, and, unfortunately, to insurance denials and delayed presentation. Long delays for patients with STEMI seeking care is a problem in many low- and middle-income countries, requiring education of the public and of all healthcare providers. Nonetheless, it appears to us that in many areas distance was a major factor, which begs the question of whether a pharmacoinvasive approach might be an important part of an optimal regional system in parts of Latin America. Finally, we wonder about the role of artificial intelligence and machine learning in developing systems such as this and fully expect that we will learn a great deal more in the next few years about how these technologies may have applicability to low- and middle-income countries around the world.

In 2007, Bill Gates in his commencement address to Harvard University stated "Humanity's greatest advances are not in its discoveries - but in how these discoveries apply". These two publications in AsiaIntervention by Drs Alexander and Mehta and their colleagues provide an admirable example of utilising what is available to enhance the use and speed of reperfusion therapy, which remains a major challenge for the majority of the world's population.

\section{Conflict of interest statement}

The authors have no conflicts of interest to declare.

\section{References}

1. Reimer KA, Jennings RB. The "wavefront phenomenon" of myocardial ischemic cell death. II. Transmural progression of necrosis within the framework of ischemic bed size (myocardium at risk) and collateral flow. Lab Invest. 1979;40:633-44.

2. Fletcher AP, Alkjaersig N, Smyrniotis FE, Sherry S. The treatment of patients suffering from early myocardial infarction with massive and prolonged streptokinase therapy. Trans Assoc Am Physicians. 1958;71:287-96.

3. Chazov EI, Matveeva LS, Mazaev AV, Sargin KE, Sadovskaia GV, Ruda MI. [Intracoronary administration of fibrinolysin in acute myocardial infarct]. [Article in Russian]. Ter Arkh. 1976;48:8-19.
4. Long-term effects of intravenous thrombolysis in acute myocardial infarction: final report of the GISSI study. Gruppo Italiano per lo Studio della Streptochi-nasi nell'Infarto Miocardico (GISSI). Lancet. 1987;2:871-4.

5. Meyer J, Merx W, Schmitz H, Erbel R, Kiesslich T, Dörr R, Lambertz H, Bethge C, Krebs W, Bardos P, Minale C, Messmer BJ, Effert S. Percutaneous transluminal coronary angioplasty immediately after intracoronary streptolysis of transmural myocardial infarction. Circulation. 1982;66:905-13.

6. Hartzler GO, Rutherford BD, McConahay DR. Percutaneous transluminal coronary angioplasty: application for acute myocardial infarction. Am J Cardiol. 1984;53:117c-21c.

7. Keeley EC, Boura JA, Grines CL. Primary angioplasty versus intravenous thrombolytic therapy for acute myocardial infarction: a quantitative review of 23 randomised trials. Lancet. 2003; 361:13-20.

8. Gersh BJ, Stone GW, White HD, Holmes DR Jr. Pharmacological facilitation of primary percutaneous coronary intervention for acute myocardial infarction: is the slope of the curve the shape of the future? JAMA. 2005;293:979-86.

9. Alexander T, Mehta S, Mullasari A, Nallamothu BK. Systems of care for ST-elevation myocardial infarction in India. Heart. 2012; 98:15-7.

10. Rao MP, Granger CB. Improving integrated care in low- and middle-income countries: the final STEMI frontier? J Interv Cardiol. 2014;27:167-70.

11. Jollis JG, Mehta RH, Roettig ML, Berger PB, Babb JD, Granger CB. Reperfusion of acute myocardial infarction in North Carolina emergency departments (RACE): study design. $\mathrm{Am}$ Heart J. 2006;152:851.e1-11.

12. Ibanez B, James S, Agewall S, Antunes MJ, BucciarelliDucci C, Bueno H, Caforio ALP, Crea F, Goudevenos JA, Halvorsen S, Hindricks G, Kastrati A, Lenzen MJ, Prescott E, Roffi M, Valgimigli M, Varenhorst C, Vranckx P, Widimský P; ESC Scientific Document Group. 2017 ESC Guidelines for the management of acute myocardial infarction in patients presenting with ST-segment elevation: The Task Force for the management of acute myocardial infarction in patients presenting with ST-segment elevation of the European Society of Cardiology (ESC). Eur Heart J. 2018;39:119-77.

13. Alexander T, Mullasari AS, Nallamothu BK. Management strategies for acute STEMI in low- and middle-income countries: experience of the Tamil Nadu ST-segment elevation myocardial infarction program. AsiaIntervention. 2021;7:27-34.

14. Mehta S, Aboushi H, Campos C, Botelho R, Fernandez F, Rodriguez D, Torres MA, Vieria D, Frauenfelder A, Pinto G, Lopez C, Acosta MI. Impact of a telemedicine-guided, populationbased, STEMI network on reperfusion strategy, efficiency, and outcomes. AsiaIntervention. 2021;7:18-26.

15. Vora AN, Holmes DN, Rokos I, Roe MT, Granger CB, French WJ, Antman E, Henry TD, Thomas L, Bates ER, Wang TY. Fibrinolysis use among patients requiring interhospital transfer for ST-segment elevation myocardial infarction care: a report from the 
US National Cardiovascular Data Registry. JAMA Intern Med. 2015;175:207-15.

16. Kite TA, Ludman PF, Gale CP, Wu J, Caixeta A, Mansourati J, Sabate M, Jimenez-Quevedo P, Candilio L, Sadeghipour P, Iniesta AM, Hoole SP, Palmer N, Ariza-Solé A, Namitokov A, Escutia-Cuevas HH, Vincent F, Tica O, Ngunga M, Meray I, Morrow A, Arefin MM, Lindsay S, Kazamel G, Sharma V, Saad A, Sinagra G, Sanchez FA, Roik M, Savonitto S, Vavlukis M, Sangaraju S, Malik IS, Kean S, Curzen N, Berry C, Stone GW, Gersh BJ, Gershlick AH; International
COVID-ACS Registry Investigators. International Prospective Registry of Acute Coronary Syndromes in Patients With COVID-19. J Am Coll Cardiol. 2021;77:2466-76.

17. Redfors B, Mohebi R, Giustino G, Chen S, Selker HP, Thiele H, Patel MR, Udelson JE, Ohman EM, Eitel I, Granger CB, Maehara A, Ali ZA, Ben-Yehuda O, Stone GW. Time Delay, Infarct Size, and Microvascular Obstruction After Primary Percutaneous Coronary Intervention for ST-Segment-Elevation Myocardial Infarction. Circ Cardiovasc Interv. 2021;14:e09879. 